\title{
UMA ANÁLISE CRÍTICA DO PROJETO ESTRATEGICO KC-390: EXPECTATIVAS E REALIDADE.
}

\author{
Mário A. Santos ${ }^{1}$
}

RESUMO: Face às crescentes necessidades brasileiras no que tange à modernização de aparatos de defesa destacam-se os imperativos relacionados à plataforma aeronáutica militar, os quais, além de contribuírem para modernização da Base Industrial de Defesa, também possuem relevância na manutenção e/ou aumento do poder aéreo brasileiro, haja vista serem ferramentas essenciais para defesa do espaço aéreo brasileiro. Neste sentido, o desenvolvimento do Projeto Estratégico KC 390 Millenium surge como opção para o aumento do poder aéreo brasileiro na medida em que irá representar um vetor de complementaridade ao Projeto F-X2 Gripen NG. Isto posto, analisar até que ponto as expectativas iniciais com relação ao KC 390 Millenium confrontam-se com a realidade do projeto, sobretudo no que concerne a uma possível complementaridade com o caça Gripen e aumento do poder aéreo brasileiro, faz-se essencial.

Palavras-chave: Projeto KC 390. Nível Tático. Poder Aéreo. Defesa Nacional. Complementaridade.

\section{1 - INTRODUÇÃO}

A importância de se analisar de forma adequada o setor de aviação brasileiro, sobretudo no que tange à plataforma aeronáutica militar, é o que motiva a elaboração deste artigo, o qual visa lançar uma dúvida acerca da efetividade do KC 390 Millenium para o aumento do poder aéreo brasileiro, tendo em vista o conceito de complementaridade e a diferença entre cargueiros de nível estratégico e de nível tático, categoria na qual o KC 390 Millenium está incluído. Para tanto, será adotada a seguinte estruturação neste artigo: a primeira seção será dedicada a um panorama geral sobre a plataforma aeronáutica militar; em seguida será abordado, de forma sucinta, o segmento aviação de transporte militar, categoria em que o KC-390 está inserido; a seção

\footnotetext{
${ }^{1}$ Doutorando em Relações Internacionais no IRI/PUC-Rio. Mestre em Relações Internacionais (PPGRI/UERJ). Especialista em História das Relações Internacionais (UERJ). Bacharel em Ciências Econômicas (IE/UFRJ).
} 
seguinte destina-se às particularidades do projeto KC-390 e às expectativas criadas por este; a quinta seção tem por objetivo abordar o modelo de inovação pelo lado da demanda adotado e como mediante este se verifica o surgimento do projeto KC-390; por fim, cabe questionar se, de fato, o KC-390 supre as necessidades da FAB no que diz respeito ao aumento do poder aéreo brasileiro.

\section{2 - PANORAMA GERAL}

Poucos são os países no mundo capazes de cumprir com os requisitos necessários em termos de tecnologia e desenvolvimento industrial que possam criar e manter empreendimentos no segmento aeronáutico, incluindo vários países de projeção internacional. Sem embargo, este é um segmento bastante fechado, com barreiras à entrada e dominado por poucos e grandes conglomerados. Dentre os países em desenvolvimento, o único que figura como um ator relevante neste segmento é o Brasil, por intermédio da Embraer. De acordo com Miranda:
A indústria aeronáutica é considerada um ativo estratégico exatamente por gerar e operar em uma engenharia altamente qualificada, base essencial de todo processo de desenvolvimento tecnológico e de inovação. Ao mesmo tempo, por sua natureza, essa indústria é obrigada a atuar permanentemente na fronteira tecnológica, seja para absorver, criar ou demandar inovações em um amplo espectro de equipamentos e produtos. Não por acaso, são poucos os países em todo o mundo que ousaram desenvolver e controlar essa indústria. O Brasil, até recentemente (início do ano 2000), ocupava posição diferenciada entre os países emergentes por conta da Embraer e de seu entorno (Miranda, 2016. p. 169).

De grande magnitude é a contribuição do segmento aeronáutico para o desenvolvimento dos países, sendo decisivo na geração de empregos, na qualificação de capital de humano, na capacitação tecnológica, na obtenção de divisas e, sobretudo, no desenvolvimento de capacidades militares, haja vista que o segmento pode ser dividido em dois setores distintos: a aviação civil/comercial e a aviação militar, esta última mais conhecida como plataforma aeronáutica militar. Por definição, o segmento de plataforma aeronáutica militar:

O segmento de plataforma aeronáutica militar abrange todo conjunto de aeronaves e equipamentos aeronáuticos 


\section{Universidade Federal Fluminense}

Instituto de Estudos Estratégicos

empregados em atividades militares, desde os aviões de combate utilizados para garantir a superioridade aérea, até as aeronaves de apoio, como transporte, treinamento, busca e salvamento (Search And Rescue - SAR). Neste sentido, esse segmento se caracteriza pela elevada amplitude e variedade das plataformas aeronáuticas de emprego militar, sendo estas agrupadas em seis subsegmentos: aviões de combate, treinamento, transporte e vigilância, além dos helicópteros e veículos aéreos não tripulados.

Também é importante ressaltar que o segmento aeronáutico alcança todo ciclo de vida dessas aeronaves, sendo este dividido em nove fases: concepção, viabilidade, definição, desenvolvimento, produção, implantação, utilização, modernização e desativação. As cinco primeiras fases são desenvolvidas pelas empresas fabricantes de aeronaves, quase sempre sob encomenda de seus clientes, no caso, as Forças Armadas. Já a fase de implantação é realizada pelo cliente em conjunto com o fabricante. Por sua vez, as fases de utilização (manutenção) e modernização, que eram quase que exclusivas dos clientes, vêm sendo crescentemente exploradas pelas próprias fabricantes de aeronaves ou empresas especializadas. Por fim, a fase de desativação, cada vez mais vinculada à questão da sustentabilidade (Ferreira, 2016. p.399400).

Outro ponto a se ressaltar sobre a plataforma aeronáutica militar é a grande importância que esta possui para a Base Industrial de Defesa (BID), sendo um dos catalisadores da revitalização e desenvolvimento desta, consoante às diretrizes estabelecidas na Estratégia Nacional de Defesa (END), por exemplo:

No esforço de modernizar a BID, buscar-se-ão parcerias com outros países, com o objetivo de desenvolver a capacitação tecnológica nacional, de modo a reduzir progressivamente a compra de serviços e de produtos acabados no exterior. A esses interlocutores estrangeiros, o Brasil deixará sempre claro que pretende ser parceiro, não cliente ou comprador. O país está mais interessado em parcerias que fortaleçam suas capacitações independentes do que na compra de produtos e serviços acabados. Tais parcerias devem contemplar, em princípio, que parte substancial da pesquisa e da fabricação seja desenvolvida no Brasil, e ganharão relevo maior quando for expressão de associações estratégicas abrangentes (Brasil, 2012. p.22).

Neste sentido, a necessidade de, continuamente, incorporar avanços tecnológicos de forma a garantir eficiência é uma característica primordial da 
plataforma aeronáutica militar, haja vista esta ter como diretriz a contínua e crescente introdução de inovações tecnológicas, as quais são geradas mediante investimentos em P\&D feitos por empresas, centros de pesquisa e universidades, o trinômio no qual se baseia a competitividade no setor. Em adição, o aumento desta competitividade em nível global vem ocasionando esforços por parte das empresas do segmento, visando diversificar as atividades em setores interrelacionados, tendo as empresas fabricantes de aeronaves militares avançado em direção à indústria espacial, o que privilegia a integração de sistemas complexos (Ferreira, 2016)

Tendência verificada no segmento, visando à expansão e diversificação das empresas, são as operações de fusão e aquisição e constituição de alianças estratégicas entre estas. Desta forma, enquanto fusões e aquisições vêm gerando um processo de concentração na estrutura organizacional do segmento, alianças estratégicas têm propiciado - ao integrar e associar os recursos financeiros e tecnológicos das empresas - o desenvolvimento e a produção de novas aeronaves militares (Ferreira, 2016)

A se destacar uma relevante característica do segmento plataforma aeronáutica militar: surge a partir de uma decisão do Estado, centrado nos imperativos de defesa nacional. No caso brasileiro, a intenção era desenvolver capacidades a serem utilizadas na produção de aeronaves de uso militar, haja vista que estas plataformas são os principais instrumentos de defesa do Estado, bem como são essenciais como um percuciente elemento de integração nacional. De acordo com Ferreira:

A indústria aeronáutica militar é de grande relevância para a defesa nacional, pois possibilita o domínio das tecnologias sensíveis, tanto as embarcadas como as utilizadas no desenvolvimento, na produção e na adaptação das aeronaves militares, permitindo o fornecimento de aeronaves militares modernas e atualizadas, além de uma maior autonomia e disponibilidade, no emprego dessas. No caso brasileiro, a indústria aeronáutica nacional possui uma posição de destaque na estrutura de defesa nacional, pois produziu internamente cerca de $60 \%$ dos aviões e $40 \%$ dos helicópteros utilizados pelas Forças Armadas brasileiras (2016, p. 438). 
Um dos subsegmentos desta plataforma aeronáutica militar é o das aeronaves de transporte e reabastecimento em voo (REVO). Estas eram avaliadas, anteriormente, pela capacidade de carga e robustez, privilegiandose as maiores e mais robustas. Era, em adição, um subsegmento dotado de reduzido dinamismo tecnológico se comparado ao das aeronaves de combate, razão que explica a aeronave Lockheed C-130 Hércules - em produção desde a década de 1950 - ainda ser a líder de vendas na categoria transporte militar de médio porte. Contudo, tais requisitos vêm se alterando no sentido de se valorizar a produção de aeronaves dotadas de maior grau tecnológico, mais eficientes, de menor consumo de combustível e custos de manutenção menores, o que representa um cenário bastante propício para 0 desenvolvimento de novas aeronaves, o que é contemplado pelo projeto KC390 (Ferreira, 2016).

Se até fins do século XX produzir aeronaves de transporte militar de médio e grande porte era algo que estava concentrado nos países EUA, Rússia e Ucrânia, a partir do início do século XXI isto começa a se modificar devido à entrada de novos fabricantes no mercado, com destaque para a Airbus, com seu A-400, e para a Embraer, com seu KC-390, modelos com capacidade de 40 e 23 toneladas, respectivamente. Sobre estes novos projetos, Ferrari (2016) identifica que:

\begin{abstract}
Ambos os programas são inovadores, pois, de um lado, incorporam significativos avanços tecnológicos e, de outro, utilizam uma ampla e internacionalizada cadeia produtiva, visando tanto a redução dos custos como a ampliação dos futuros demandantes. A Airbus e a Embraer são empresas líderes no mercado de aviação comercial e estão buscando diversificar suas atividades produtivas, aproveitando as sinergias existentes, além de buscar compensar as flutuações do mercado aeronáutico civil (2016, p. 417)
\end{abstract}

Empresa chave e líder do setor de defesa brasileiro, a Embraer - surge na década de 1960, criada pelo Estado, e após passar por grave crise no início dos anos, foi privatizada em 1994 - é a mais importante empresa do segmento plataforma aeronáutica militar e responsável pela concepção, desenvolvimento 
e produção do projeto KC-390, em parceria com a Força Aérea Brasileira (FAB). Nos últimos anos a empresa tem dedicado atenção especial ao setor de defesa brasileiro, haja vista a atuação nos projetos F-X2 e KC-390. Buscando reforçar, via desenvolvimento de novos serviços e aeronaves, a presença da empresa no segmento militar, a Embraer constituiu, em 2011, a Embraer Defesa e Segurança (EDS), de atuação restrita ao setor de defesa (Ferreira, 2016).

Cumpre registrar que, seguindo tendência mundial no setor, a EDS - por meio da criação de novas empresas ou aquisição de já existentes no mercado - vem realizando investimentos de grande magnitude na BID brasileira, constituindo-se em um conglomerado aeroespacial de acentuada relevância para o desenvolvimento tecnológico brasileiro, gerando inovações e produzindo capacitação tecnológica no setor de defesa (Ferreira, 2016).

Concluindo este panorama, é essencial falar sobre o papel da FAB no que tange aos esforços de desenvolvimento tecnológico da plataforma aeronáutica militar e do subsegmento aeronaves de transporte e REVO, no caso aqui considerado, o KC-390. Neste aspecto, de acordo com o Coronel Aviador Júlio Cesar Cardoso Tavares:

\begin{abstract}
Alinhada com os documentos emitidos pelo MD, a FAB, em seu recente documento de planejamento Concepção Estratégica Força Aérea 100 - Diretriz do Comando da Aeronáutica (DCA) 11-45, de 2016, insere em sua Missão-Síntese a participação nas atividades de estímulo à indústria de defesa e orienta que a sustentação logística para garantir as condições operacionais dos meios de Força Aérea deve ser integrada à BID (Tavares, 2017. p. 15).
\end{abstract}

Não obstante, é bastante clara a missão da FAB presente na Dimensão 222, a qual possui dentre seus Projetos Estratégicos o KC-390, o que já denota um significativo envolvimento da FAB com a Embraer, formando uma parceria fundamental para o sucesso do projeto, que irá gerar ganhos positivos para o desenvolvimento da BID e que se insere no modelo que Ribeiro (2017) denomina de inovação pelo lado da demanda. Desta forma:

\footnotetext{
${ }^{2}$ Manter a soberania do espaço aéreo e integrar o território nacional com vistas à defesa da pátria, para tanto é essencial controlar, defender e integrar os 22 milhões de $\mathrm{Km}^{2}$ que compreendem o território brasileiro.
} 
Para cumprir sua missão a contento, com base no conceito de ciclo de vida dos equipamentos que utiliza, existem na $F A B$, em algumas de suas divisões e subdivisões, competências ligadas à aquisição e modernização/upgrade tecnológico dos equipamentos do seu acervo. É importante salientar que a aquisição realizada pela $F A B$ não se resume ao ato licitatório, envolvendo outras atividades, tais como concepção, engenharia, teste e avaliação. Ademais, não raro, diferentemente da maioria dos adquirentes do setor público, a aeronáutica adquire equipamentos que não estão na "prateleira", ou seja, compra o desenvolvimento de produtos de defesa. Um exemplo recente e emblemático dessa modalidade de aquisição realizada pela $F A B$ foi a encomenda do desenvolvimento de um avião cargueiro tático, em 2009, junto à Embraer, dando ensejo ao programa KC-390 (Ribeiro, 2017, p. 235)

\section{3 - O SETOR DE AVIAÇÃO DE TRANSPORTE MILITAR}

Composto por várias categorias de aeronaves divididas de acordo com a capacidade de carga (pequeno, médio e grande), o setor de aviação de transporte militar é um segmento bastante amplo, estando incluído neste as aeronaves de REVO, que, em geral, são versões de aeronaves de transporte militar ou plataformas flexíveis ${ }^{3}$ (Ferreira, 2016).

Anteriormente concentrado em poucas empresas, provenientes dos EUA, Rússia e Ucrânia, e de lento dinamismo tecnológico, atualmente o setor se encontra um pouco mais segmentado, com a entrada da Airbus (Europa), da Embraer Defesa e Segurança (EDS), da Hal (Índia), da Kawasaki Heavy Industries (Japão) e da Alenia (Itália). Observa-se, também, neste segmento, empresas como a Boeing e a UAC vêm construindo parcerias com empresas de outros países no intuito de compartilhar o desenvolvimento de novas aeronaves e ter acesso a outros mercados, a exemplo da joint-venture entre Boeing e Embraer para comercialização do KC-390 (Ferreira, 2016).

No que tange à aviação de transporte militar brasileira, esta, até bem recentemente, operava com as aeronaves C-767 Boeing, C-105 Amazonas, C-

\footnotetext{
${ }^{3}$ Plataformas flexíveis são aeronaves militares que podem ser utilizadas tanto para transporte militar quanto para reabastecimento aéreo (REVO), bastando, para isso, adequá-las antes da missão.
} 
99, C-97 Brasília, C-98 Caravan, C-95 Bandeirante, U-35 Learjet e C-130 Hércules. Dentre as Ações de Força Aérea relacionadas com a Tarefa de Sustentação de Combate a serem exercidas pela aviação de transporte no Brasil, destacam-se: Assalto Aeroterrestre; Busca e Salvamento; Evacuação Aeromédica; Exfiltração Aérea; Infiltração Aérea; Transporte; REVO; Transporte Aéreo-Logístico; Combate a Incêndios; e Transporte Especial (FAB, 2018).

Cabe ressaltar que, dentro do espectro de modernização das Forças Armadas, a FAB, desde 2010, vem se destacando em treinamentos onde as aeronaves de transporte possuem um papel estratégico e não somente de apoio. A se ressaltar, também, as missões de transporte de mantimentos, água potável e remédios (Haiti, em 2010), o transporte de órgãos para transplantes, o ressurgimento dos Pelotões de Fronteira do Exército, e o repatriamento de brasileiros no Líbano, Suriname e outros (FAB, 2018).

Neste contexto, e atendendo aos anseios pela revitalização da BID, que passa pela modernização da frota aérea brasileira, conforme consta na Dimensão 22, deu-se o desenvolvimento de uma aeronave de transporte e REVO (plataforma flexível) brasileira que viesse a substituir as antigas aeronaves C-130 Hércules. Esta nova aeronave, fruto de uma parceria entre a FAB e a EDS, é cercada das mais diversas expectativas: potencial de desenvolvimento da plataforma aeronáutica militar, lucratividade na exportação para outros países, substituição eficaz dos C-130 utilizados pela FAB, capacitação tecnológica, dentre outras.

A justificar o alto grau de expectativa com relação ao $\mathrm{KC}$-390 pode-se elencar, na visão de Ferreira (2016), os seguintes fatores: a base de mercado da aeronave é bastante ampla, tendo em vista que visa substituir a principal aeronave de transporte militar do mundo, o C-130 Hércules, que, apesar de ser um grande sucesso comercial, se encontra bastante desatualizado pois data da década de 1950; o KC-390 praticamente não possui concorrentes no segmento, bem como é o único projeto novo; a parceria entre a Embraer e a Boeing visando alavancar o mercado para aeronave; e o fato de o KC-390 ser uma plataforma flexível, podendo ser utilizado para as mais diversas funções. 
Segundo estimativas da Embraer, feitas em outubro de 2018, o KC-390 possui mercado potencial de $U \$ 60$ bilhões para a próxima década, sendo seu principal concorrente o antigo $\mathrm{C}-130$, que até hoje domina o mercado no segmento. Apontado pela Embraer como um avião de transporte tático ${ }^{4}$ (e não estratégico) desenvolvido para estabelecer novos padrões em seu segmento, apresentando o menor custo de ciclo de vida do mercado, o KC-390 é capaz de executar diversas missões tais como transporte de carga, lançamento de tropa de paraquedistas, REVO, busca e salvamento, evacuação aeromédica, combate a incêndios e apoio a missões humanistas, podendo transportar até 26 toneladas de carga a uma velocidade máxima de $870 \mathrm{~km} / \mathrm{h}$, além de operar em ambientes hostis e em pistas danificadas (DefesaNet, 2018).

\section{4 - O PROJETO KC-390}

Tendo em vista que manter a soberania do espaço aéreo é missão da $F A B$, faz-se mister a existência de uma força aérea dotada de infraestrutura técnica e recursos humanos que a capacite ao cumprimento de sua respectiva missão. Desta forma, no intuito de cumprir a missão que the cabe, a FAB possui capacitações ligadas à aquisição e modernização tecnológica dos equipamentos que possui. Neste sentido, as aquisições feitas pela $F A B$ não se resumem apenas a atos licitatórios pois envolvem outras atividades como a concepção, engenharia, teste e avaliação, ou seja, adquire o desenvolvimento de produtos de defesa. Exemplo concreto desta atuação da $F A B$ é o próprio projeto KC-390, que se embasa na encomenda do desenvolvimento de um cargueiro multimissão, em 2009, à Embraer (Ribeiro, 2017).

De acordo com reportagem publicada:

A EMBRAER anunciou o projeto da aeronave de transporte tático com rampa traseira C-390 na LAAD 2007. O projeto poderá ser o maior e mais ambicioso projeto da empresa. O C390 seria um avião de transporte militar que usaria

\footnotetext{
${ }^{4}$ Essa seria uma das críticas e limitações a serem imputadas ao KC-390, ser uma aeronave tática e não estratégica, como era o KC-137.
} 
componentes e estruturas da família de jatos EMB-170 e EMB190. Na LAAD 2009 a EMBRAER e a FAB assinaram um contrato para o desenvolvimento do KC-390. A designação foi mudada pois a missão de reabastecimento em voo passou a ser parte da capacidade da aeronave. O projeto também foi alterado pois as especificações da FAB forçaram uma revisão do projeto, que ficou bem alterado externamente com 0 aumento do tamanho das asas e a cauda em T. As turbinas serão bem mais potentes que as usadas no EMB-190 e os aviônicos serão mais adequados às operações militares com o uso de óculos de visão noturna (Sistema de Armas, s/d)

Assim, expectativas apontam que o KC-390 irá "significar um salto operacional para as Forças Armadas e um avanço para a indústria aeronáutica brasileira", devendo se tornar, ao longo dos próximos anos, "a espinha dorsal da aviação de transporte” da FAB (FAB, 2018). Tendo em vista cortes orçamentários ocorridos, motivados pela grave crise econômica que se instaurou no país ao longo dos últimos anos, e problemas relacionados a testes com um dos protótipos da aeronave, o cronograma proposto de entrega das primeiras aeronaves foi substancialmente alterado. Inicialmente, a previsão de entrega estava agendada para ocorrer em 2016. Posteriormente, alterou-se para 2018. Contudo, apenas em setembro de 2019 a Embraer entregou à FAB a primeira aeronave KC-390. Em junho de 2020 a terceira aeronave, atualmente denominada de KC-390 Millenium, foi incorporada à FAB. A se ressaltar que o KC-390 - que contou desde 2008 com investimentos governamentais da ordem de $\mathrm{R} \$ 5$ bilhões no projeto e com a compra inicial de 28 (vinte e oito) aeronaves, feita pelo governo, ao custo de $R \$ 7,2$ bilhões será futuramente fabricado por uma joint-venture entre a Embraer (que detém $51 \%$ da joint-venture) e a Boeing (que detém $49 \%$ da joint-venture). (Folha de São Paulo, 2019)

Ainda no que concerne às expectativas geradas pelo KC-390, identifica Ribeiro (2017) que:

A investigação da encomenda do avião KC-390 também permitiu que fossem identificados alguns problemas concernentes à implementação do referido programa. Inicialmente, cumpre ressaltar o atraso em seu cronograma decorrente de dificuldades orçamentárias do governo federal. Trata-se de um problema observado de maneira recorrente nos 
programas de defesa do país, e que acabou por adiar em dezoito meses a certificação final do novo produto. Há inclusive o temor de que este atraso no cronograma tenha afetado potenciais vendas a outros clientes $(2017$, p. 13)

Inserindo-se no rol do modelo de inovação pelo lado da demanda, a encomenda do KC-390 pela FAB teve grande aporte de capital do Estado (Ribeiro, 2017). Desta forma, o KC-390, maior aeronave já produzida pela indústria aeronáutica brasileira, vem estabelecer um novo e moderno padrão no segmento aeronaves de transporte militar de médio porte, tendo em vista o desempenho e a capacidade de carga apresentados, bem como os avançados sistemas de missão e de voo, o que faz com que o KC-390 voe mais alto e mais rápido que seu maior concorrente, o C-130. A previsão é que a nova aeronave traga expressivos benefícios em termos de mobilidade para seus operadores, reduzindo, assim, o tempo da missão (Aero Magazine, 2016).

Outro ponto de destaque é que o KC-390 possui tecnologia no estado da arte em termos de guerra eletrônica, capacidade ativa e passiva contra mísseis infravermelhos, blindagem, sistema de comando de voo de última geração e reduzidos custos operacionais e de manutenção, especificidades estas que provocaram um acentuado otimismo por parte da Embraer e do governo brasileiro com relação às perspectivas de exportação da aeronave (Ribeiro, 2017). Tais perspectivas têm como um de seus pilares a intenção da Embraer em tornar o KC-390 a aeronave de menor custo operacional de seu segmento e de preço extremamente competitivo. Neste sentido, cálculos iniciais da Embraer estimavam em US\$7,5 por milha voada o custo operacional do KC390, bem abaixo dos US $\$ 13$ referentes ao $\mathrm{C}-130 \mathrm{~J}^{5}$, o maior concorrente da aeronave brasileira. Entretanto, após mudanças no projeto inicial do KC-390, que teria partes em comum com a aeronave EMB-390, (também fabricada pela Embraer) tais estimativas foram descartadas (Sistema de Armas, s/d).

Assim, desenvolvido para substituir os C-130 utilizados pela FAB e para competir com esta aeronave no mercado global, importante ressaltar as principais diferenças entre o KC-390 e o C-130: em primeiro lugar, o KC-390

\footnotetext{
${ }^{5}$ Versão modernizada do C-130 Hércules.
} 
possui o compartimento de carga mais largo e mais alto, sendo capaz de transportar cargas que não são possíveis de serem transportadas pelo C-130, que tem capacidade de transportar cerca de $70 \%$ dos itens da OTAN, o que é considerado uma das grandes fraquezas do C-130. A título de exemplo, veículos blindados como o Pátria AMV 8 × 8 e o LAV-25 apenas podem ser transportados no C-130 se alguns de seus itens forem retirados, operação que pode ser demorada, impedindo, assim, que os blindados entrem em imediatamente em operação. Entretanto, se transportados no KC-390, ao saírem da aeronave estes blindados já estão prontos para o combate (Sistema de Armas, s/d). Ademais, o KC-390 será capaz de operar em pistas não pavimentadas em qualquer lugar. Em termos monetários, apesar de ser um modelo mais novo e moderno que o C-130, o preço de mercado do KC-390 é inferior ao de seu principal concorrente, o que faz do KC-390 uma aeronave de grande potencial de venda.

Cumpre frisar que a encomenda do KC-390 feita pela FAB insere-se plenamente nas diretrizes da END no que concerne ao reaparelhamento e modernização das forças armadas, bem como na Dimensão 22. Desta maneira, constata-se que o desenvolvimento desta aeronave cumpre uma dupla e extremamente significativa função, qual seja: suprir as necessidades operacionais da $\mathrm{FAB}$ no que tange à substituição dos antigos C-130 pelo novo cargueiro multimissão; e estimular o desenvolvimento e a capacitação tecnológica da plataforma aeronáutica militar. Em adição, haja vista o segmento ${ }^{6}$ ser um ativo estratégico devido ao elevado transbordamento tecnológico que propicia, o desenvolvimento do KC-390 irá gerar inúmeros benefícios para a BID brasileira.

\footnotetext{
${ }^{6} \mathrm{O}$ Projeto F-X2 pode ser considerado um exemplo concreto de transbordamento tecnológico tendo em vista os vários acordos de compensação existentes, bem como a exigência contratual de transferência de tecnologia.
} 


\section{5 - INOVAÇÕES PELO LADO DA DEMANDA GERADAS PELA FAB E 0 SURGIMENTO DO PROJETO KC-390}

A indústria aeronáutica brasileira surgiu no contexto da Guerra Fria, quando o Estado assumiu o protagonismo no processo de consolidação do parque industrial brasileiro. $E$ pode-se afirmar que esta indústria sempre esteve intrinsecamente relacionada aos programas engendrados pela $F A B$, os quais foram essenciais para o desenvolvimento da capacidade tecnológica do setor, sobretudo os projetos de aquisição e desenvolvimento de aeronaves. Neste sentido, o papel do Estado se mostra bastante decisivo ao considerarmos que a Embraer foi criada em 1969 pelo antigo Ministério da Aeronáutica para fabricação da aeronave EMB-110 Bandeirante, que foi desenvolvida pelo antigo Centro Técnico da Aeronáutica (CTA), hoje Departamento de Ciência e Tecnologia Aeroespacial (DCTA) (Ribeiro, 2017).

À época de sua criação, a Embraer não possuía a expertise necessária para a produção em série de aeronaves, o que fez com que a FAB adquirisse 0 EMB-326 Xavante mediante compra de projeto sob licença da italiana Aer Machi. A produção do Xavante acabou capacitando a Embraer para produzir o Bandeirante. Posteriormente, outras aeronaves também se valeram do conhecimento tecnológico obtido no processo. No tocante ao Bandeirante, tamanho foi seu sucesso que este, originalmente um projeto para uso exclusivo da $F A B$, tornou-se uma importante aeronave na aviação regional (Ribeiro, 2017).

Em seguida, com relação à aeronave de treinamento militar EMB-312 Tucano, mais uma vez pode-se constatar a atuação decisiva da FAB no processo de desenvolvimento de uma aeronave, feito, novamente, em parceria com a Embraer. Nos mesmos moldes deu-se o desenvolvimento do EMB-314 Super Tucano, evolução do EMB-312. Destaque especial cabe ao Projeto AMX, parceria entre os governos de Brasil e Índia que gerou uma série de capacitações tecnológicas para Embraer, sendo a partir deste que a Embraer passou a dominar a integração de equipamentos eletrônicos em rede e que 
começou a operar fly-by-wire, tecnologia presente no desenvolvimento do KC390 e um dos diferenciais que este possui (Ribeiro, 2017).

Embora os programas engendrados pela $F A B$ sob os moldes da inovação pelo lado da demanda tenham gerado impactos positivos na consolidação da indústria aeronáutica brasileira e criado expectativas futuras, conforme o ocorrido no caso do Programa AMX, problemas conjunturais vividos pelo Brasil, ocasionando falta de recursos orçamentários e descontinuidade de programas, trouxeram uma dura realidade às ambiciosas expectativas: o governo foi obrigado a interromper o contrato e não efetuou a compra das aeronaves anteriormente previstas nem tampouco foram alocados recursos para compra de peças de reposição para as aeronaves e/ou atualizações/evoluções desta.

E com o projeto KC-390 o caminho seguido parece ser o mesmo: grandes expectativas que quando confrontadas com a realidade mostram diferenças bastante significativas. Atrasos no cronograma inicialmente acordado, bem como falta de recursos financeiros por parte do Estado já impactou negativamente no desenvolvimento do projeto. Decerto que o surgimento de uma crise financeira mundial contribuiu decisivamente para a redução dos gastos. A entrega das aeronaves foi postergada por 4 (quatro) vezes, sendo a primeira unidade entregue apenas em setembro de 2019, bem como houve acidentes com os protótipos da aeronave. Por outro lado, o fato de o KC 390 Millenium ser um cargueiro de nível tático e não estratégico pode vir a ser um fator negativo em termos de complementaridade no futuro. Não obstante, cabe um breve histórico sobre o surgimento do projeto KC-390.

\section{1 - O Surgimento do Projeto KC-390}

O início do século XXI impõe às forças armadas a necessidade de modernização e reaparelhamento, tendência verificada em vários países. No Brasil, com a criação, em 1999, do Ministério da Defesa (MD) e o processo de revitalização da BID, esta tendência se manifesta de forma inequívoca. Neste contexto, a Aeronáutica começa a pensar sobre a modernização de sua frota 
aérea, que no segmento aviação de transporte militar tem na aeronave C-130 Hércules sua base. Colocam-se, então, as seguintes opções: fazer o upgrade nos C-130 mediante troca de peças ou substituí-los pela evolução do modelo, o C-130J. Havia, também, a possibilidade de se adquirir o desenvolvimento de uma nova aeronave mediante encomenda e parceria com a Embraer, algo que a FAB já fizera em outras ocasiões (Ribeiro, 2017).

De forma a se decidir pela melhor opção possível procedeu-se a um estudo de viabilidade no qual foram consideradas inúmeras variáveis ${ }^{7}$ até que se chegasse à decisão final: seria mais vantajosa a opção pelo desenvolvimento de uma nova aeronave segundo requisitos estipulados pela FAB, aquisição esta que seria precedida pela produção de dois protótipos desta nova aeronave. Importante ressaltar que esta decisão final estava em consonância com os anseios da Embraer que, em 2005, antes mesmo do início das negociações com a $F A B$, por intermédio da área de inteligência de mercado da empresa, havia identificado a viabilidade de lançamento de um novo avião de transporte militar (Ribeiro, 2017). Desta forma, apontam Dalla Costa e Souza-Santos:

Segundo o diretor de mercado para a área de defesa, Fernando Ikedo, a ideia nasceu em 2005 como um estudo interno visando produzir um cargueiro militar de médio porte. $\mathrm{Na}$ primeira etapa, quebrou-se o mercado de aeronaves militares em quatro faixas considerando a capacidade de carga: leves (até 5 toneladas); médias (de 5 a 10); pesados (de 10 a 20); e superpesados (mais de 20), sendo selecionado o estudo para oferecer aeronaves na faixa de 5 a 20 toneladas, por ser essa a mais numerosa do mercado, constituindo cerca de 2,8 mil aeronaves, excluindo China, Coreia do Norte e Irã por razões políticas. O passo seguinte foi considerar os cargueiros com mais de 25 anos de uso que deviam ser substituídos nos próximos anos, chegando a 1,6 mil. Retirando desse total o mercado dos grandes produtores (Estados Unidos, Ucrânia e Rússia) e os países que equacionaram o problema do transporte militar, sobra um mercado potencial de 700 unidades (2011, p. 183)

\footnotetext{
${ }^{7}$ Para subsidiar a tomada de decisão foram consideradas questões logísticas, operacionais, orçamentárias, administrativas, prazo de entrega, riscos, custo-benefício, impactos positivos a serem gerados na BID, montante a ser investido e acesso a linhas de financiamento. Mediante análise e ponderação de todas essas variáveis chegou-se à decisão final: a opção pela compra do desenvolvimento de uma nova aeronave.
} 
Logo, o KC-390 é uma aeronave concebida a partir de uma iniciativa interna da Diretoria de Projetos Avançados (DAP) da Embraer, que pensou na possibilidade de se aproveitar partes já conhecidas de outras aeronaves para construir, a um custo reduzido de desenvolvimento, uma aeronave de transporte militar. Assim, após o desenvolvimento da ideia na DAP, esta foi apresentada à área de negócios da Embraer. Em seguida, a Embraer autorizou investimentos em testes no intuito de melhor definir o produto, e, por fim, a ideia concebida pela empresa foi apresentada ao MD. Já em 2007, a Embraer apresentou ao Estado Maior da Aeronáutica (EMAER) a proposta para 0 desenvolvimento da aeronave. Em 2009 alguns aspectos relacionados ao projeto foram detalhados e iniciaram-se as discussões com a FAB, a fim de se definir uma especificação inicial acerca desta aeronave, iniciando-se a fase de anteprojeto, que corresponde à fase mais importante do projeto, onde são estudadas as dimensões, perfilagem, estimativas de peso, características iniciais de estabilidade e controle, ergonomia, configurações, soluções inovadoras, dentre outras. (Ribeiro, 2017).

Sobre o anteprojeto do K-390, aponta Ribeiro:

O anteprojeto do KC-390 dividiu-se em duas fases: a primeira, de estudos conceituais (EC), e a segunda, de estudos preliminares (EP). A fase de estudos conceituais foi levada a cabo pela Embraer antes de ser contratada pela FAB para o desenvolvimento. Nessa fase, a Embraer esboçou a solução, com base em requisitos de mercado, definidos pela área de inteligência de mercado. A fase de estudos conceituais exige uma interação constante entre as áreas de anteprojeto e inteligência de mercado da empresa (2017, p. 254)

Com relação ao projeto, cabe ressaltar que a Embraer já havia realizado testes aerodinâmicos no modelo antes do contrato de desenvolvimento com a $F A B$, logo, antes da assinatura do contrato com a FAB para o desenvolvimento do KC-390, a Embraer já havia realizado atividades de mitigação de risco e refinamento de projeto durante a etapa de estudos conceituais. Isto possibilitou 
à Embraer dar subsídios para que a $\mathrm{FAB}$ elaborasse seus requisitos e obter uma concepção mais detalhada do produto. Quanto aos requisitos emitidos pela $F A B$, estes eram parte do pedido de oferta de desenvolvimento da aeronave e foram incorporados ao contrato assinado entre a FAB e a Embraer (Ribeiro, 2017).

No que concerne ao contrato entre FAB e Embraer, tem-se que:

O contrato assinado com a $F A B$ no valor $R \$ 3,028$ bilhões em abril de 2009, durante a LAAD, cobria o desenvolvimento e produção de dois protótipos, mais toda a documentação e ferramental associados. O cronograma do projeto tem 3 fases com duração total de 7 anos sendo a primeira fase para definição de componentes e parcerias (2 anos); a segunda fase para Detalhamento do Projeto e Produção de 2 Protótipos (total da $1^{\underline{a}}$ e $2^{\underline{a}}$ Fase $=5$ anos) e a terceira fase sendo a Fase de testes e qualificação dos Protótipos (2 anos). Na feira aérea de Farnborough, no Reino Unido, em julho de 2010, a FAB anunciou a encomenda de 28 aeronaves KC-390. A FAB estima que o projeto, desenvolvimento, produção e compra deve custar cerca de US\$ 5 bilhões (Sistema de Armas, s/d) 


\section{Cronograma Inicial de Desenvolvimento do KC-390}

\begin{tabular}{|c|c|c|c|c|c|c|c|}
\hline 2009 & 2010 & 2011 & 2012 & 2013 & 2014 & 2015 & 2016 \\
\hline $\begin{array}{c}\text { Estudos } \\
\text { Preliminares }\end{array}$ & $\begin{array}{c}\text { Definições } \\
\text { Iniciais }\end{array}$ & $\begin{array}{c}\text { Definições } \\
\text { Conjuntas }\end{array}$ & \multicolumn{5}{c|}{ Projeto Detalhado e Certificação } \\
\hline
\end{tabular}

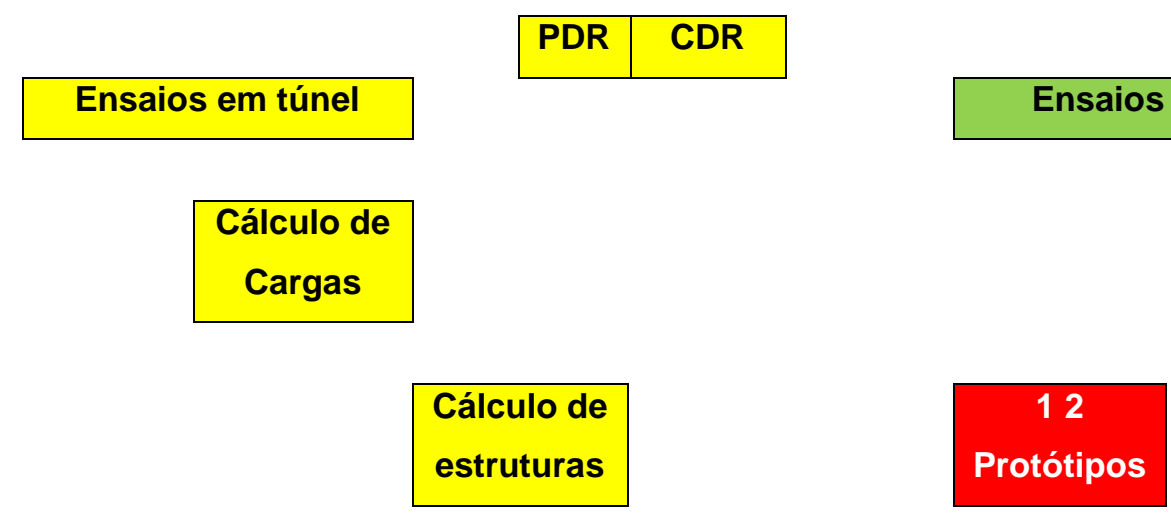

\section{Procura e seleção de parceiros e}

fornecedores

\section{IOC}

Liberação de

desenhos

Fonte: Ribeiro (Apud Affonso, 2014)

Tendo por base o cronograma acima descrito, pode-se observar as etapas referentes ao desenvolvimento do KC-390 que são apontadas por Ribeiro (2017): com a assinatura do contrato em abril de 2009 e o início de vigência em $1^{\circ}$ de maio de 2009, a primeira etapa corresponde aos estudos preliminares, que se inicia em maio de 2009 e termina em maio de 2010. Nesta etapa é que se iniciou o processo de seleção e contratação de fornecedores. Ao término desta, teve início a etapa de definições iniciais, etapa em que foi feita a avaliação e detalhamento do projeto inicial. Em seguida veio a etapa de definições conjuntas, etapa em que todas as conexões e interfaces entre os

\footnotetext{
${ }^{8}$ Refere-se ao cronograma inicial do projeto, não incluindo os atrasos devido aos inúmeros problemas ocorridos ao longo dos anos. Serviu mais como uma estimativa, ou melhor, uma expectativa que não se realizou.
} 
sistemas da aeronave são cuidadosamente definidas, visando detalhar as peças e os conjuntos estruturais que Ihes são pertinentes. Cumpre ressaltar que as três etapas iniciais foram concluídas em setembro de 2012.

Sobre o fim das três etapas iniciais e a importância da etapa definições conjuntas, identifica o autor que:

Vencida essa etapa, dois passos decisivos podem ser dados: um, a liberação dos desenhos técnicos para a área de manufatura, que começa, então, a fabricar as primeiras peças para a montagem dos protótipos previstos; e 0 outro, a largada da campanha de comercialização do KC390. É quando a Embraer sai a campo para discutir as configurações do avião que interessam a cada cliente potencial, bem como preços e condições de entrega (Ribeiro, apud Mendes, 2013, p. 63)

Em outubro de 2012 teve início a última etapa, a de projeto detalhado e certificação, que tinha como principais atividades previstas a construção de dois protótipos da aeronave e a certificação civil e militar (Ribeiro, 2017)

Em março de 2013 deu-se a critical design review ${ }^{9}(C D R)$, que contou com presença de militares da FAB e representou um marco significativo na etapa final do cronograma de desenvolvimento da aeronave. Confirmaram-se as configurações aerodinâmicas e estruturais, a arquitetura e a instalação dos sistemas e outros elementos críticos da aeronave. Foram apresentados aos militares da FAB que estavam presentes as ferramentas e os modelos utilizados na fabricação do KC-390. Por último houve a apresentação do simulador de engenharia e do modelo em tamanho real da cabine de pilotagem. Assim, tendo por base a CDR, constatou-se que o projeto alcançara maturidade exigida para que fosse iniciada a fabricação dos protótipos (Ribeiro, 2017).

Segundo o CEO da EDS em 2013, Luiz Carlos Aguiar, a CDR foi de suma importância para os rumos do projeto. Nas palavras dele: "Saímos destas discussões convictos de que a fabricação dos protótipos pode ser

\footnotetext{
${ }^{9}$ Em português, revisão crítica de projeto.
} 
iniciada"(...). "Concluímos uma etapa importante do Programa KC-390 e, desta forma, prestamos contas à FAB do trabalho realizado" (Embraer, 2013).

Em outubro de 2014 ocorreu a primeira apresentação pública do primeiro protótipo da nova aeronave, em Gavião Peixoto (SP), na fábrica da Embraer. Já em fevereiro de 2015 a Embraer realizou o primeiro voo experimental do KC-390, e em outubro do mesmo ano iniciou-se a campanha de testes em voo, a fim de se avaliar o desempenho e robustez da aeronave, tendo em vista que a cada voo a aeronave é avaliada nas mais diversas situações no que concerne à altitude, velocidade e configuração (Ribeiro, 2017). Com previsão de duração de dois anos - ao término deste período de campanha de testes em voo a aeronave obteria as certificações civil e militar, podendo ser utilizada em missões reais - e tendo se iniciado em 2015, até janeiro de 2019 a aeronave ainda não tinha obtido a certificação militar, somente a civil.

Com relação à montagem do segundo protótipo da aeronave, esta foi concluída em março de 2016 e logo em seguida iniciou-se a campanha de testes em voo. A expectativa era que, com os dois protótipos em campanha de testes em voo, a Embraer obtivesse as certificações Initial Operational Capability (IOC) e Full Operational Capability (FOC) e a entrega da primeira unidade da aeronave fosse realizada no prazo inicialmente previsto em contrato. Sobre este adiamento, em discordância com o cronograma inicial que pode ser visualizado acima, aponta o autor:

Cabe salientar que as entregas iniciais e a IOC e a FOC sofreram uma dilatação em seu prazo (...) em decorrência da falta de recursos. Com o alongamento, a IOC foi para o segundo semestre de 2017 e a FOC para o segundo semestre de 2018. Diante disso, a entrega da primeira unidade seriada está prevista para o primeiro semestre de 2018 (Ribeiro, 2017, p. 257).

Entretanto, até maio de 2019 a entrega da primeira unidade da aeronave à $F A B$ ainda não havia ocorrido, o que apenas se deu em setembro de 2019. Dado situação semelhante estar em curso no que tange à aquisição dos caças de combate é essencial se demonstrar uma visão crítica ao se analisar este 
Projeto. Ademais, conforme será abordado na próxima seção, a própria presença dos KC-390 não garante o pleno exercício de poder aéreo por parte do Brasil, dado que estes são aeronaves táticas e não estratégicas, diferentemente das antigas aeronaves KC-137.

Importante abordar algumas parcerias internacionais acordadas no âmbito do Projeto KC-390, haja vista serem relevantes para projeção de poder brasileiro e para geração de divisas para o país. Neste sentido destaca-se a assinatura de declaração de intenções entre Brasil e Colômbia ${ }^{10}$, visando a participação da Colômbia no programa de desenvolvimento e na produção do KC-390. Portugal também figura nesta lista pois no ano de 2010 assinou uma declaração de intenções com o Brasil, visando participar do desenvolvimento e produção do KC-390. Em adição, o Chile é outro país sulamericano a figurar como parceiro internacional do programa, assim como a Argentina. No plano europeu, a República Tcheca também se mostra presente. Cabe ressaltar que todos estes parceiros internacionais do programa demonstraram clara intenção de adquirir unidades do KC-390, a serem utilizadas em suas respectivas forças armadas (Aero Magazine, 2016).

Por fim, embora não esgotando o tema aqui desenvolvido, resta investigar em que media o desenvolvimento do KC-390 irá possuir complementaridade com o Projeto F-X2, no intuito de equacionar os requerimentos do poder aéreo brasileiro.

\section{6 - O PROJETO KC-390 À LUZ DA ÓTICA DE COMPLEMENTARIDADE COM O PROJETO F-X2}

Em se falando de expectativas e realidade, e sobretudo no que concerne ao preenchimento das capacidades militares brasileiras de forma a dotar o país de poder aéreo, cabe questionar se o KC-390, desenvolvido e propagandeado como a futura espinha dorsal da aviação de transporte militar brasileira, seria de fato uma aeronave adequada para tanto e representaria um vetor de

\footnotetext{
${ }^{10}$ Até o momento, a Colômbia figura como o único país sulamericano a fazer parte da Organização do Tratado do Atlântico Norte (OTAN).
} 
complementaridade ao Projeto F-X2 Gripen NG. Neste aspecto, poder-se-ia colocar uma dúvida que nortearia toda a análise, a saber: seria o KC-390 uma aeronave estratégica com elevada capacidade de realizar reabastecimento em voo e de longo alcance, de forma a preencher as necessidades da construção do poder aéreo brasileiro?

Em primeiro lugar, tomo como parâmetro a concepção do teórico do poder aéreo Giulio Douhet, que afirmava:

Dominar o ar significa estar em condições de impedir o voo do inimigo, a mesmo tempo em que garantimos essa faculdade para nós mesmos (...) Aquele que possui o domínio do ar e possui uma força atacante adequada e capaz de proteger seu território e mares circundantes contra ataques aéreos e impedir o inimigo de efetuar qualquer ação aérea em proveito de seus componentes terrestre e naval (Douhet, 1988, p.48)

Neste sentido, deve ser dado destaque ao fato de que, até 2013, a FAB possuía quatro aeronaves de reabastecimento em voo de longo alcance e com elevada capacidade de carga - a versão militar do Boeing B707-320C, o KC137 - que operavam desde 1986 e já estavam perto do fim do ciclo de vida, com no máximo cinco anos mais de uso contínuo. Ocorre, porém, que em junho de 2013, houve um grave acidente com uma dessas aeronaves quando em uma missão no Haiti, quase chegando a explodir e causando perda total nesta. Tal fato, aliado ao fim do ciclo de vida da aeronave, motivou a decisão do Alto Comando da Aeronáutica de encerrar as atividades com estas aeronaves, perdendo, assim, a FAB as aeronaves de capacidade estratégica que possuía (Moure, 2014).

Havia, à época, um projeto que se encontrava em fase de apresentação de propostas e que tinha por objetivo adquirir/desenvolver aeronaves que viessem a substituir os antigos KC-137, o denominado Projeto KC-X2. Contudo, devido ao conturbado momento político e econômico vivido pelo Brasil, este projeto careceu de continuidade (Moure, 2014). Importante ressaltar que nesta mesma época a CDR referente ao projeto KC-390 acontecia, o que pode denotar a intenção de não se dar continuidade ao KC-X2 por se achar que os KC-390 seriam suficientes para os objetivos da FAB. No que tange a um 


\section{Universidade Federal Fluminense \\ Instituto de Estudos Estratégicos}

suposto pensamento neste sentido, segundo o Coronel Aviador Marcel Gomes Moure, instrutor de voo e líder de elemento em REVO, com mais de 1200:00H e que operou em mais de 46 países nos cinco continentes:

Na área de Aviação de Caça, a totalidade dos deslocamentos das Unidades de Caça teve suporte as aeronaves FAB 2401, FAB 2402, FAB 2403 e FAB 2404 (matrículas dos KC-137) que serviram na Força Aérea no período de 1986 a 2013. Somente com o emprego do KC-137 era possível deslocar "vetores" de caça aos extremos do Brasil, com capacidade de reabastecimento em voo sem igual na história da FAB (Moure, 2014, p. 17).

Ainda segundo Moure:

As dimensões continentais do país e a recente aprovação da nova aeronave de caça, o programa F-X2, exigirá um suporte de reabastecimento em voo que permita cobrir todo o território nacional, a qualquer hora e local. Isso somente se faz exequível com um "vetor" de grande capacidade logística de carga, passageiro e, sobretudo, transferência de combustível, em quantidade e vazão que atendam ao Gripen NG e demais vetores de combate do Poder Aéreo (Moure, 2014, p. 22).

O KC-137 era um quadrimotor a jato, com 40 toneladas de carga útil disponível na sua configuração totalmente cargueiro (full cargo) e que concentrava sua função estratégica no REVO de caças F-SEM, F-2000 Mirage e A1 justamente pelo fato de ser capaz de conduzir combustível (90.000 litros) à maior distância e maior altitude, com possibilidade de transferência de 1700 litros por minuto e pela atuação como aeronave de transporte de longo alcance e grande capacidade estratégica para apoio ao emprego do poder aérea pela FAB (Moure, 2014) Por outro lado, a Embraer nunca investiu em aeronaves de grande porte, e o KC-390, embora mais moderno e de melhor desempenho que o C-130, não possui a capacidade operacional que o antigo KC-137. Até que ponto este poderia ser a espinha dorsal da aviação de transporte militar brasileira diante deste quadro e na ausência de complementaridade efetiva com o Gripen NG?

Decerto que uma Força Aérea necessite de um avião de caça que permita a esta contrapor-se a toda e qualquer ameaça externa, entretanto deve-se ter em mente que as guerras do século XXI não serão somente decididas pelos chamados vetores de caça, mas sim por uma rede completa e 
integrada de data link, sustentada por aeronaves de comunicação e controle avançados e REVO que propicie uma ampla cobertura de segurança em todo 0 território nacional, sobretudo para países que possuem as dimensões do Brasil. Tais aeronaves são denominadas de High Value Aircraft devido à importância estratégica que possuem no teatro de operações aéreo, e sua ausência inviabiliza o emprego do poder aéreo em sua total plenitude, o que se torna um fato inquestionável para o Brasil, tendo em vista a Dimensão 22.

Neste contexto, ainda que o KC-390 seja mais moderno e superior ao C130, o corner business da Embraer se encontra no nível tático e não no nível estratégico, segmento do KC-137, o que faz com que a FAB careça de um vetor estratégico de REVO. A nível comparativo, um KC-137 era capaz de levar o dobro de carga de um moderno KC-390. Em adição, o programa F-X2 demanda, visando a operação de toda sua capacidade instalada, uma aeronave estratégica com capacidade de longo alcance, autonomia, carga e REVO, características não presentes no KC-390 e, sendo assim, este não é capaz de suprir a demanda gerada pelos Gripen NG, ou seja, não haverá uma complementaridade tamanha que possa vir a manifestar o poder aéreo brasileiro em sua totalidade.

Diante do acima exposto, cabe repetir a pergunta que inaugura esta seção, qual seja: seria o KC-390 uma aeronave estratégica com elevada capacidade de realizar reabastecimento em voo e de longo alcance, de forma a preencher as necessidades da construção do poder aéreo brasileiro? A resposta demanda uma reflexão dos fatos alegados e se coaduna com a intenção deste texto de propor um debate acerca das expectativas e realidade que cercam o projeto KC-390.

\section{7 - CONSIDERAÇÕES FINAIS}

Há uma necessidade indiscutível de reaparelhamento das Forças Armadas e esta é uma tendência que vem se fazendo presente desde o início do século $X X I$, de sorte que os países vêm empreendendo esforços no sentido de se adequarem aos condicionantes de uma ordem mundial com distribuição 
difusa de poder e na qual os imperativos de segurança e defesa são preceitos que dominam as políticas dos Estados. Assim é que capacidades militares, base industrial de defesa e desenvolvimento tecnológico são demandas bastante urgentes para os países.

Nesta dinâmica se insere o Brasil, que busca envidar esforços em prol de uma revitalização e modernização de sua BID e que tem na indústria aeronáutica um vetor estratégico de extrema importância, haja vista o papel da plataforma aeronáutica militar no desenvolvimento tecnológico e econômico do país, setor este que tem na Embraer sua mais importante empresa.

Dentro desta conjuntura buscou-se analisar um projeto específico de aquisição de uma aeronave, bem como seus desdobramentos para o segmento aviação de transporte militar de médio porte e como ferramenta importante para o fortalecimento do poder aéreo brasileiro. Assim, ao se analisar o Projeto KC-390 nos confrontamos com inúmeras expectativas criadas referentes a seu desenvolvimento, muitas das quais aparentemente não se concretizaram ou nasceram dotadas de uma grandiosidade sem precedentes, sobretudo ao se dimensionar de forma um tanto quanto elevada o papel da nova aeronave para a FAB.

Importante compreender nesta análise a lógica do modelo de inovação pelo lado da demanda e a atuação da FAB neste modelo, que em parceria com a Embraer, vem sendo decisiva para o desenvolvimento tecnológico do país. Por outro lado, a falta de um eficiente planejamento de defesa no país pode ser a chave para explicar a falta de recursos orçamentários e outros problemas inerentes ao atraso no cronograma inicial de desenvolvimento da aeronave KC390.

Outro fator que sugere a falta de um planejamento de defesa eficiente no país é a não complementaridade entre os projetos F-X2 e KC-390, ambos vistos como essenciais para a missão da FAB na Dimensão 22 e para obter-se o que Douhet chama de domínio do ar, o alicerce fundamental do poder aéreo. Quais teriam sido as razões que levaram à priorização dos projetos F-X2 e KC- 
390 e o abandono do projeto KC-X2 dado que ser este último o que, de fato, complementaria o projeto F-X2 é algo que valeria a pena ser investigado.

Por fim, deixo claro que o estudo ora apresentado não esgota, de forma alguma, o tema, que é dotado de grande riqueza. Contudo, pode vir a contribuir no sentido de gerar importantes reflexões e debates sobre o projeto KC-390.

\section{REFERÊNCIAS BIBLIOGRÁFICAS}

AERO MAGAZINE. Novo cargueiro da Embraer vai concorrer com o avião militar mais vendido da história. Aero Magazine. 26 de agosto de 2016. Disponível em https://aeromagazine.uol.com.br/artigo/conheca-o-kc-390-onovo-rival-do-hercules 2760.html. Consultado em 22 de maio de 2019.

BRASIL. Ministério da Defesa. Política Nacional de Defesa (PND) e Estratégia Nacional de Defesa (END); Brasília, 2012.

DALLA COSTA, A.; SOUZA-SANTOS, E. R. Embraer diversifica projetos na área militar: o novo cargueiro C-390. Economia \& Tecnologia, V. 24, n. 7, p. 179-186, jan/mar, 2011.

DEFESANET. KC-390 possui mercado potencial de US\$ 60 bilhões, prevê Embraer. DefesaNet, 25 de outubro de 2018. Disponível em www.defesanet.com.br/kc390/noticia/30978/-KC-390-possui-mercado-

potencial-de-US\%24-60-bilhoes--preve-Embraer/. Consultado em 27 de maio de 2019.

DOUHET, G. O Domínio do Ar. Rio de Janeiro. Instituto Histórico-Cultural da Aeronáutica, 1988.

EMBRAER. Força Aérea Brasileira e Embraer Defesa \& Segurança concluem Revisão Crítica de Projeto do KC-390. Press Release, 25 de março de 2013. Disponível em https://defense.embraer.com/br/pt. Consultado em 24 de maio de 2019.

FOLHA DE SÃO PAULO. Após atraso e quase desastre com protótipo, Embraer entrega cargueiro para FAB. São Paulo. Publicado em 2 de abril de 2019. Disponível em https://www1.folha.uol.com.br/poder/2019/04/apos-atrasoe-quase-desastre-com-prototipo-embraer-entrega-cargueiro-para-fab.shtml

FERREIRA, M. J. B. Plataforma Aeronáutica Militar. In: Mapeamento da Base Industrial de Defesa. Brasília. ABDI / IPEA, 2016.

FORÇA AÉREA BRASILEIRA. Revista Dimensão 22. Brasília, 2019. Disponível em http://www.fab.mil.br/dimensao22/download/REVISTA D22.pdf. Consultado em 25 de maio de 2019. 
FORÇA AÉREA BRASILEIRA. FAB - Dia do Correio Aéreo Nacional e da Aviação de Transporte - 12 de Junho. Publicado em 11 de junho de 2018. Disponível em http://www.fab.mil.br/transporte. Consultado em 26 de maio de 2019.

MIRANDA, Z. Sistema de Inovação do Setor Aeronáutico: desafios e oportunidades para o Brasil. In: NEGRI, F., SQUEFF, F. H. S. (Org.) Sistemas Setoriais de Inovação e Infraestrutura de Pesquisa no Brasil. Brasília. IPEA, 2016.

MOURE, M. G. Projeto KC-X2: Uma Necessidade Estratégica para O Emprego do Poder Aéreo Brasileiro. Monografia apresentada ao Departamento de Estudos da Escola Superior de Guerra como requisito à obtenção do diploma do Curso de Altos Estudos de Política e Estratégia (CAEPE), 2014. Rio de Janeiro, 2014.

RIBEIRO, C. G. Desenvolvimento Tecnológico Nacional: O Caso KC-390. In: RAUEN, A. T. (Org.). Políticas de Inovação Pelo Lado da Demanda no Brasil. Brasília. IPEA, 2017.

RIBEIRO, C. G. Encomendas Tecnológicas Realizadas pela FAB: o programa KC-390. In: Revista Radar, n. 52, agosto de 2017b.

SISTEMA DE ARMAS. KC-390 - Versões Especiais. Sistema de Armas. [s.d.]. Disponível em http://www.sistemasdearmas.com.br/ca/macx00kc390.html. Consultado em 28 de maio de 2019.

TAVARES, J. C. C. Contribuições do Projeto F-X2 - Gripen NG para a Base Industrial de Defesa (BID): estudo sobre os benefícios esperados para a BID nacional. Monografia apresentada ao Departamento de Estudos da Escola Superior de Guerra como requisito à obtenção do diploma do Curso de Altos Estudos de Política e Estratégia (CAEPE), 2017. Rio de Janeiro, 2017. 